\title{
Effect of an essential oils blend on growth performance, and selected parameters of oxidative stress and antioxidant defence of Escherichia coli challenged piglets
}

\author{
X.R. Jiang ${ }^{1,2,4}$, X.L. Li ${ }^{2}$, A. Awati ${ }^{3}$, H. Bento ${ }^{3}$, H.J. Zhang ${ }^{2}$ and V. Bontempo ${ }^{1,4}$ \\ ${ }^{1}$ Università degli Studi di Milano, Department of Health, Animal Science and Food Safety, 20133 Milan, Italy \\ ${ }^{2}$ Chinese Academy of Agricultural Sciences, Feed Research Institute, 100081 Beijing, China \\ ${ }^{3}$ Danisco Animal Nutrition, Dupont Industrial Biosciences, SN8 1XN Marlborough, United Kingdom
}

KEY WORDS: antioxidant status, Escherichia coli challenge, essential oils, growth performance, weaned piglets

Received: 28 December 2015

Revised: 28 November 2016

Accepted: $\quad 7$ March 2017

\begin{abstract}
This study evaluated the effect of diet supplementation with an essential oil blend (13.5\% thymol and $4.5 \%$ cinnamaldehyde, EO) on growth performance and selected parameters of oxidative stress and antioxidant defence in Escherichia coli challenged piglets. Ninety-six weaned piglets were allocated into 4 experimental treatments 6 replicates per treatment with 4 piglets per replicate) for 35 days arranged in a $2 \times 2$ factorial design: diet [a basal diet without additive (CT) or with $50 \mathrm{mg} \cdot \mathrm{kg}^{-1} \mathrm{EO}$ ] and $E$. coli challenge [sham (-) or infected $(+)]$. On day 8 , half of the piglets from each dietary group was orally inoculated with $4 \mathrm{ml}$ of $E$. coli 0149:F4 (K88). The $E$. coli challenge increased the level of malondialdehyde (MDA) in piglet serum on day $9(P<0.01)$, and tended to reduce average daily feed intake $(P=0.08)$ and average daily gain $(P=0.08)$ from day 7 to day 35 . Dietary EO addition did not affect growth performance but tended to reduce MDA content in piglet serum in comparison with CT group on day $9(P=0.07)$. Neither EO addition nor $E$. coli challenge influenced antioxidative enzymes (superoxide dismutase and glutathione peroxidase) activity. The obtained results suggest that EO rich in thymol and cinnamaldehyde had tendency to reduce serum lipid peroxidation level by EO addition, however no such effect was observed in piglets challenged by $E$. coli. So, further studies are needed to confirm the EO influence on systemic antioxidant defence of weaned piglets.
\end{abstract} ${ }^{4}$ Corresponding author:
e-mail: xianrenjiang@126.com,
valentino.bontempo@unimi.it
(Lykkesfeldt and Svendsen, 2007). In our previous study it was stated that ETEC challenge reduced the inhibition capacities of superoxide anions and hydroxyl radical (Jiang et al., 2014). The oxidative stress results from overproduction of reactiveoxygen species and reactive-nitrogen species (Valko et al., 2007), which alters the antioxidant defence system in animal body (Han et al., 2011). 
Previous studies indicated that certain active substances in essential oils (carvacrol, thymol and cinnamaldehyde) exert beneficial effects on animal performance and intestinal health in pigs due to their antimicrobial properties ( $\mathrm{Si}$ et al., 2006; Trevisi et al., 2007). In addition, beneficial effects of essential oils are connected with antioxidant properties of bioactive volatile compounds (Amorati et al., 2013). In vitro studies have demonstrated that thymol and carvacrol (Lagouri et al., 1993) and cinnamaldehyde (Mancini-Filho et al., 1998) exhibit antioxidative properties. However, little is known about their antioxidative effect in vivo, in particular in the combination of essential oils. Boudry and Perrier (2008) observed that thymol and cinnamaldehyde induced anion secretion in piglet small intestine via cholinergic pathway, which may suggest that thymol and cinnamaldehyde may exert a promoting antioxidative effect in the small intestine of weaning piglets.

Therefore, the aim of the present study was to assess the effects of essential oils blend (containing $13.5 \%$ thymol and $4.5 \%$ cinnamaldehyde, EO) on growth performance and antioxidant status of weaned piglets under Escherichia coli challenged condition.

\section{Material and methods}

\section{Animals and treatments}

The experiment was carried out at the facility of Animal Production Research and Teaching Centre of the Polo Veterinario, Università degli Studi di Milano (Lodi, Italy). The experimental protocol was approved by the Ethics Committee of the Università degli Studi di Milano (Protocol No. Dan.Piglet. EOSW0511, March $8^{\text {th }}$, 2011).

At weaning ( $24 \pm 2$ days), 96 crossbreed (Stambo HBI $\times$ Dalland 40$)$ piglets $(8.63 \pm 1.69 \mathrm{~kg})$ were allotted to 4 treatments in a randomized design with 6 replicates per treatment with 4 piglets per replicate. Animals were housed in 24 slatted floor pens $(1.2 \times$ $1 \mathrm{~m}$ ) equipped with two water nipples and selffeeder (4 piglets/pen). Ventilation was achieved by single and variable-speed fans linked to temperature sensors. The temperature inside the building was approximately $28^{\circ} \mathrm{C}$ at the start of the trial, adjusted weekly until a final temperature of $26^{\circ} \mathrm{C}$. Piglets were raised for 35 days in 4 different groups with a $2 \times 2$ factorial design comparing oral $E$. coli O149:F4 (K88) challenge [sham $(-)$ or infected $(+)$ ] and different dietary treatments [basal weaning diet without additive (CT) or with $50 \mathrm{mg} \cdot \mathrm{kg}^{-1}$ essential
Table 1. Ingredient and chemical composition of the diets, as fed basis

\begin{tabular}{|c|c|c|}
\hline Indices & $\begin{array}{l}\text { Pre-starter diet } \\
\text { days } 0-14\end{array}$ & $\begin{array}{l}\text { Starter diet } \\
\text { days } 14-35\end{array}$ \\
\hline \multicolumn{3}{|l|}{ Ingredients, $\mathrm{g} \cdot \mathrm{kg}^{-1}$} \\
\hline flacked wheat & 245.2 & 150.0 \\
\hline wheat & 70.0 & 212.6 \\
\hline barley & 177.5 & 200.0 \\
\hline flacked maize & 100.0 & 104.0 \\
\hline whey powder & 90.0 & 40.0 \\
\hline herring meal & 55.0 & 50.0 \\
\hline soya protein concentrate & 90.0 & 45.0 \\
\hline soyabean meal $(48 \% \mathrm{CP})$ & 100.0 & 86.0 \\
\hline wheat middlings & - & 50.0 \\
\hline dextrose & 10.0 & - \\
\hline soyabean oil & 33.0 & 33.0 \\
\hline dicalcium phosphate & 13.0 & 13.0 \\
\hline calcium carbonate & 5.0 & 7.0 \\
\hline L-lysine & 3.0 & 3.5 \\
\hline vitamin-mineral premix & 2.5 & 2.5 \\
\hline L-threonine & 3.2 & 1.2 \\
\hline DL-methionine & 1.6 & 1.0 \\
\hline tryptophan & - & 0.2 \\
\hline sodium chloride & 1.0 & 1.0 \\
\hline phytase $^{2}$ & 0.1 & 0.1 \\
\hline feed additive premix ${ }^{3}$ & -10.25 & -10.25 \\
\hline \multicolumn{3}{|c|}{ Calculated energy and nutrient content, $\mathrm{g} \cdot \mathrm{kg}^{-1}$} \\
\hline digestible energy, $\mathrm{MJ} \cdot \mathrm{kg}^{-1}$ & 14.44 & 14.00 \\
\hline crude protein & 215.1 & 193.1 \\
\hline ether extract & 54.5 & 57.5 \\
\hline crude fibre & 26.1 & 32.1 \\
\hline $\mathrm{Ca}$ & 8.9 & 8.4 \\
\hline$P$ & 7.2 & 7.2 \\
\hline
\end{tabular}

${ }^{1}$ vitamin-mineral premix supplied per $\mathrm{kg}$ final feed: IU: vit. A 10500 , vit. $D$ 2500; mg: vit. $E 15$, vit. $B, 1.5$, vit. $B$ 3.8, vit. $B$ o. 025 , vit. $B_{6} 1.6$, calcium pantotenate 12 , nicotinic acid 15 , biotin 0.15 , folic acid 0.5, vit. $\mathrm{K}_{3} 3$, Fe 100, Cu 6, Co 0.75, Zn 150, Mn 65, I 0.75, Se 0.4, ethoxyquin 150; ${ }^{2}$ phytase: Phyzyme XP TPT (Danisco Animal Nutrition, Marlborough, UK); ${ }^{3}$ feed additive premix: control group - no additive; EO group - $250 \mathrm{mg} \cdot \mathrm{kg}^{-1}\left(50 \mathrm{mg} \cdot \mathrm{kg}^{-1} \mathrm{EO}\right.$ product which contained $13.5 \%$ thymol and $4.5 \%$ cinnamaldehyde)

oils blend (EO)]. The EO product (Enviva ${ }^{\mathrm{TM}} \mathrm{EO}$, Danisco Animal Nutrition, Marlborough, UK) contained $13.5 \%$ thymol and $4.5 \%$ cinnamaldehyde, and the supplemental dose was adjusted on the basis of our previous studies (Jiang et al., 2015a,b). The thymol and cinnamaldehyde contents in the diet were analysed and confirmed by high performance liquid chromatography (HPLC). Diets were formulated to meet the NRC requirements (2012) for pigs (Table 1). The EO product was manually mixed with a small quantity of the basal diet $(2 \%)$ and thereafter add to residual basal diet. Diet was free of any antibiotic growth promoters or antibiotic growth promoter alternatives. Both pre-starter and starter 
diets were milled through $1.5 \mathrm{~mm}$ particle size mill and stored in a cool dry place. Pre-starter feeds were fed to piglets from 0 to 14 day of the trial, and the starter feeds were fed to animals for the last three weeks.

On day 8 of the trial, the piglets housed in one side of the room were orally injected with $4 \mathrm{ml}$ solution containing $10^{9} \mathrm{CFU}$ of E. coli O149: F4 (K88)-positive strain (Lombardy and Emilia Romagna Experimental Zootechnic Institute, Brescia, Italy). The inoculum containing the K88-positive ETEC strain, isolated from pigs with colibacillosis, also expressed heat-labile (LT) and heat-stable B (STb) toxins (Loos et al., 2012), and was prepared accordingly to the methods of Bosi et al. (2004). A one-way traffic path was implemented to prevent non-challenged pigs to contact with challenged pigs.

\section{Growth performance, blood sampling, and samples analysis}

Piglets were weighed individually at weaning (day 0 ) and subsequently every week until the end of trial. Feed intake was recorded each day and the residual feed was weighted at the same day as weighing piglets. Growth performance (average daily feed intake, average daily gain and gain to feed ratio) were calculated for each pen.

At day 0,9 (one day after $E$. coli challenge) or 35 (end of the trial), the same piglet in each pen with an initial body weight close to the pen average was selected to collect blood sample (a total of 24 samples per each time point). Blood samples were collected via jugular puncture into $9 \mathrm{ml}$ vacutainers without anticoagulant and were immediately centrifuged at $3000 \mathrm{~g}$ for $10 \mathrm{~min}$ at $4{ }^{\circ} \mathrm{C}$ to separate the serum. The collected serum was aliquoted and stored at $-80{ }^{\circ} \mathrm{C}$ until further analysis of antioxidant indicators.

The serum selected parameters of oxidative stress and antioxidant defence were analysed in duplicate using assay kits according to the manufacturer's instructions (Nanjing Jiancheng Bioengineering Institute, Nanjing, China). Malondialdehyde (MDA) concentration was analysed with 2-thiobarbituric acid, and the change in absorbance was read at a wavelength of $532 \mathrm{~nm}$. Total superoxide dismutase (T-SOD) activity was detected by monitoring the inhibition of nitro blue tetrazolium reduction, and the change in absorbance was read at a wavelength of $450 \mathrm{~nm}$. The glutathione peroxidase (GSH-Px) activity was measured with 5,5'-dithiobis- $p$-nitrobenzoic acid, and the change in absorbance at $412 \mathrm{~nm}$ was recorded. All absorbance levels were measured using a UV-visible spectrophotometer (JASCO Europe S.R.L, Cremella, Italy).

\section{Statistical analysis}

The data were analysed as a completely randomized design with a $2 \times 2$ factorial treatment arrangement by ANOVA using the MIXED procedure of SAS v. 9.2 (SAS Inst. Inc., Cary, NC, USA). The model included effects of diet (CT or EO), E. coli challenge $(+$ or -$)$ and their interaction. The pen represented the experimental unit for growth performance, while the individual piglets were the experimental units for serum parameters of oxidative stress and antioxidant defence. Treatment comparisons were done using a Tukey's post-hoc test. An alpha level of 0.05 was used for determination of statistical significance and of 0.10 for the determination of statistical tendencies.

\section{Results and discussion}

The $E$. coli challenge tended to decrease average daily feed intake (ADFI) and average daily gain (ADG) of piglets from day 7 to day $35(P=0.08$ for both parameters; Table 2). This is consistent with previous studies that showed that the performance of weaned pigs was impaired by enterotoxigenic E. coli challenge (Liu et al., 2013; Bontempo et al., 2014; Jiang et al., 2015a). Previous studies about the effect of essential oils on growth performance in piglets have been inconsistent, showing either improvement (essential oils mixture containing menthol and cinnamaldehyde; Maenner et al., 2011) or no effect (essential oils mixture containing thymol and cinnamaldehyde; Jiang et al., 2015b). In the present study, addition of EO to diet did not affect the growth performance regardless the status of $E$. coli challenge $(P>0.05)$. Maenner et al. (2011) added a mixture of essential oils characterized by either menthol (Mentha arvensis) or cinnamaldehyde (Cinnamomum aromaticum) to the diet at a dose of $0.3 \mathrm{~g} \cdot \mathrm{kg}^{-1}$ of feed to improve the feeding efficiency of weaned piglets. Such results suggest that the kind of used essential oils or the supplemental doses determine the effect of supplementation with essential oil on the performance of weaning piglets (Windisch et al., 2008). Further studies are needed to examine whether increasing doses of the EO blend containing thymol and cinnamaldehyde would exert growth promoting effect in weaning piglets.

The activities of SOD and GSH-Px, and the content of MDA reflect the antioxidant and lipid peroxidation status of cultured cells and animal tissues (Efe et al., 1999). There was neither effect of diet nor challenge on antioxidant status on day 0 (data not shown). The $E$. coli challenge significantly increased MDA content $(P<0.01)$ on day 9 (one 
day after challenge) (Table 3). Ünlü et al. (2001) observed that $E$. coli-injected rats had significantly elevated serum level of MDA. The increased serum content of MDA in the challenged piglets may be due to the induced free radical formation (Ünlü et al., 2001) or antimicrobial-mediated cell death (Wang and Zhao, 2009). Our previous study indicated that the E. coli challenge increased the populations of faecal E. coli and coliforms of weaned piglets within 6 days post challenge while dietary EO containing thymol and cinnamaldehyde reduced the faecal coliforms count on day 6 after challenged with E. coli K88 (Jiang et al., 2015a). Francis (2002) reported that susceptibility of pigs to ETEC is mainly caused by the expression and exposure of its receptors on the intestinal luminal surface, while systemic effects might be limited. Antioxidant enzymes such as T-SOD and GSH-Px play important role in the antioxidant defence system (Jaeschke, 1995). In our study, no ETEC challenge effects on T-SOD and GSH-Px activities were observed, which is in agreement with our previous study (Jiang et al., 2014). Several studies reported that essential oils containing carvacrol, cinnamaldehyde and thymol excert antioxidant activity (Lagouri et al., 1993; ManciniFilho et al., 1998; Zeng et al., 2015). In the present study, dietary EO addition tended to reduce MDA
Table 2. Effects of essential oil blend (EO) supplementation on growth performance of weaned piglets challenged with Escherichia coli

\begin{tabular}{|c|c|c|c|c|c|}
\hline \multirow[b]{2}{*}{ Indices } & \multicolumn{2}{|c|}{ Body weight, kg } & \multicolumn{3}{|c|}{ Days 7-35 } \\
\hline & day 7 & day 35 & $\begin{array}{l}A D G^{1} \\
g \cdot d^{-1}\end{array}$ & $\begin{array}{l}\left.A D F\right|^{2} \\
g \cdot d^{-1}\end{array}$ & $\mathrm{G}: \mathrm{F}^{3}$ \\
\hline \multicolumn{6}{|l|}{ Interaction effects ${ }^{4}$} \\
\hline CT- & 11.04 & 25.28 & 509 & 909 & 0.556 \\
\hline EO- & 11.30 & 25.92 & 522 & 930 & 0.561 \\
\hline $\mathrm{CT}+$ & 10.89 & 23.33 & 444 & 835 & 0.531 \\
\hline $\mathrm{EO}+$ & 11.10 & 24.71 & 486 & 881 & 0.552 \\
\hline SEM $(n=6)$ & 0.75 & 1.25 & 27 & 34 & 0.013 \\
\hline \multicolumn{6}{|l|}{ Main effects } \\
\hline \multicolumn{6}{|l|}{ E. coli challenge } \\
\hline- & 11.17 & 25.60 & $516^{x}$ & $920^{x}$ & 0.558 \\
\hline+ & 10.99 & 24.02 & $465^{y}$ & $858^{y}$ & 0.541 \\
\hline $\operatorname{SEM}(n=12)$ & 0.53 & 0.88 & 19 & 24 & 0.009 \\
\hline \multicolumn{6}{|l|}{ Diet } \\
\hline $\mathrm{CT}$ & 10.96 & 24.31 & 477 & 872 & 0.543 \\
\hline EO & 11.20 & 25.32 & 504 & 905 & 0.556 \\
\hline SEM $(n=12)$ & 0.53 & 0.88 & 19 & 24 & 0.009 \\
\hline \multicolumn{6}{|l|}{$P$-value } \\
\hline E. coli challenge & 0.82 & 0.22 & 0.08 & 0.08 & 0.19 \\
\hline diet & 0.76 & 0.43 & 0.32 & 0.34 & 0.32 \\
\hline $\begin{array}{l}\text { E. coli } \\
\text { challenge } \times \text { diet }\end{array}$ & 0.97 & 0.77 & 0.62 & 0.72 & 0.55 \\
\hline
\end{tabular}

${ }^{1} \mathrm{ADG}$ - average daily gain; ${ }^{2} \mathrm{ADFI}$ - average daily feed intake; ${ }^{3} \mathrm{G}: \mathrm{F}$ - gain to feed ratio; ${ }^{4} \mathrm{CT}$ - basal diet without additive; EO - CT $+50 \mathrm{mg} \cdot \mathrm{kg}^{-1}$ essential oils blend (thymol and cinnamaldehyde); +/- - presence or absence of $E$. coli challenge; $x y$ - means with different superscripts within the same column show values with tendency to differ $(P<0.10)$

Table 3. Effect of essential oil blend (EO) supplementation on serum antioxidant property of weaned piglets challenged with Escherichia coli

\begin{tabular}{|c|c|c|c|c|c|c|}
\hline \multirow[b]{2}{*}{ Indices } & \multicolumn{3}{|l|}{ Day 9} & \multicolumn{3}{|l|}{ Day 35} \\
\hline & $\begin{array}{l}\mathrm{MDA}^{1} \text { content, } \\
\mathrm{nmol} \cdot \mathrm{ml}^{-1}\end{array}$ & $\begin{array}{l}\text { T-SOD }{ }^{2} \text { activity, } \\
\mathrm{U} \cdot \mathrm{ml}^{-1}\end{array}$ & $\begin{array}{l}\text { GSH-Px activity, } \\
\mathrm{U} \cdot \mathrm{ml}^{-1}\end{array}$ & $\begin{array}{l}\text { MDA content, } \\
\mathrm{nmol} \cdot \mathrm{ml}^{-1}\end{array}$ & $\begin{array}{l}\text { T-SOD activity, } \\
\mathrm{U} \cdot \mathrm{ml}^{-1}\end{array}$ & $\begin{array}{l}\text { GSH-Px activity, } \\
\mathrm{U} \cdot \mathrm{ml}^{-1}\end{array}$ \\
\hline \multicolumn{7}{|l|}{ Interaction effects ${ }^{4}$} \\
\hline CT- & 1.73 & 107 & 471 & 1.92 & 116 & 623 \\
\hline EO- & 1.35 & 112 & 546 & 1.94 & 124 & 650 \\
\hline $\mathrm{CT}+$ & 2.25 & 109 & 507 & 1.86 & 115 & 630 \\
\hline $\mathrm{EO}+$ & 2.10 & 104 & 568 & 2.13 & 119 & 668 \\
\hline SEM $(n=6)$ & 0.14 & 4 & 40 & 0.31 & 4 & 32 \\
\hline \multicolumn{7}{|l|}{ Main effects } \\
\hline \multicolumn{7}{|l|}{ E. coli challenge } \\
\hline- & $1.54^{b}$ & 110 & 508 & 1.93 & 120 & 637 \\
\hline+ & $2.17^{a}$ & 107 & 537 & 2.00 & 117 & 649 \\
\hline SEM $(n=12)$ & 0.10 & 3 & 28 & 0.22 & 3 & 23 \\
\hline \multicolumn{7}{|l|}{ Diet } \\
\hline CT & $1.99^{x}$ & 108 & 489 & 1.89 & 115 & 627 \\
\hline EO & $1.72^{y}$ & 108 & 557 & 2.04 & 121 & 659 \\
\hline SEM $(n=12)$ & 0.10 & 3 & 28 & 0.22 & 3 & 23 \\
\hline \multicolumn{7}{|l|}{$P$-value } \\
\hline E. coli challenge & $<0.01$ & 0.51 & 0.48 & 0.83 & 0.45 & 0.71 \\
\hline diet & 0.07 & 0.98 & 0.12 & 0.65 & 0.12 & 0.32 \\
\hline E. coli challenge $\times$ diet & 0.43 & 0.25 & 0.87 & 0.70 & 0.65 & 0.86 \\
\hline
\end{tabular}

${ }^{1}$ MDA - malondialdehyde; ${ }^{2}$ T-SOD - total superoxide dismutase; ${ }^{3} \mathrm{GSH}-\mathrm{Px}$ - glutathione peroxidase; ${ }^{4}$ see Table $2 ;$ ab - means with different superscripts within the same column are significantly different $(P<0.05)$; ${ }^{x y}$ - means with different superscripts within the same column show groups with tendency to differ $(P<0.10)$ 
content on day $9(P=0.07)$ but no influence on T-SOD and GSH-Px activities was observed on day 9 and 35, which suggested that the EO supplementation might improve the non-enzymatic reactions of antioxidant defence system, attenuate the lipid peroxidation and has potential to enhance the capacity to scavenge free radicals. Although the main effect of EO addition on MDA level was statistically significant, the influence of EO supplementation on MDA content in the plasma of challenged piglets on day 9 was not significant $(\mathrm{CT}+$ (2.25) vs EO+ $(2.10 ; P=0.85)$ and less pronounced than in the plasma of unchallenged animals (CT(1.73) vs EO- $(1.35 ; P=0.25)$, which may be due to the limited effect of EO on oxidative stress under the bacterial challenge. Zeng et al. (2015) reported that the supplementation of $250 \mathrm{mg} \cdot \mathrm{kg}^{-1} \mathrm{EO}$ that contained at least $4.5 \%$ cinnamaldehyde and $13.5 \%$ thymol increased total antioxidant capacity in the serum of weaned piglets. In the present study the EO were added at a dose of $50 \mathrm{mg} \cdot \mathrm{kg}^{-1}$, so the further studies are needed to examine whether the increasing doses of EO blend rich in thymol and cinnamaldehyde would improve its antioxidative activity in animals.

\section{Conclusions}

In conclusion, the obtained results suggest that an essential oils (EO) blend rich in thymol and cinnamaldehyde added into diet does not significantly affect growth performance of weaned piglets. There was observed a tendency of EO addition to reduce serum lipid peroxidation level, however there was no such effect observed in piglets challenged by E. coli. So, further studies should be conducted to investigate more antioxidant indices and to examine higher doses of EO and so to confirm the efficacy of EO on systemic antioxidant defence in weaned piglets.

\section{Acknowledgements}

This study was financially supported by Danisco Animal Nutrition, DuPont Industrial Biosciences, Marlborough (UK). The authors appreciate the staff of the Animal Production Research and Teaching Center of the Polo Veterinario dell'Università degli Studi di Milano who took care of the animals, and Dr D. Sciacca for the assistance during the project.

\section{References}

Amorati R., Foti M.C., Valgimigli L., 2013. Antioxidant activity of essential oils. J. Agric. Food Chem. 61, 10835-10847, https:// doi.org/10.1021/jf403496k

Bontempo V., Jiang X.R., Cheli F., Lo Verso L., Mantovani G., Vitari F., Domeneghini C., Agazzi A., 2014. Administration of a novel plant extract product via drinking water to post-weaning piglets: effects on performance and gut health. Animal 8 , 721-730, https://doi.org/10.1017/S175173111400041X

Bosi P., Casini L., Finamore A., Cremokolini C., Merialdi G., Trevisi P., Nobili F., Mengheri E., 2004. Spray-dried plasma improves growth performance and reduces inflammatory status of weaned pigs challenged with enterotoxigenic Escherichia coli K88. J. Anim. Sci. 82, 1764-1772, https://doi. org/10.2527/2004.8261764x

Boudry G., Perrier C., 2008. Thyme and cinnamon extracts induce anion secretion in piglet small intestine via cholinergic pathways. J. Physiol. Pharmacol. 59, 545-552

Efe H., Değer O., Kirci D., Karahan S.C., Örem A., Calapoğlu M., 1999. Decreased neutrophil antioxidative enzyme activities and increased lipid peroxidation in hyperlipoproteinemic human subjects. Clin. Chim. Acta 279, 155-165, https://doi. org/10.1016/S0009-8981(98)00178-8

Fairbrother J.M., Nadeau E., Gyles C.L., 2005. Escherichia coli in postweaning diarrhea in pigs: an update on bacterial types, pathogenesis, and prevention strategies. Anim. Health Res. Rev. 6, 17-39, https://doi.org/10.1079/AHR2005105

Francis D.H., 2002. Enterotoxigenic Escherichia coli infection in pigs and its diagnosis. J. Swine Health Prod. 10, 171-175

Han J., Shuvaev V.V., Muzykantov V.R., 2011. Catalase and superoxide dismutase conjugated with platelet endothelial cell adhesion molecule antibody distinctly alleviate abnormal endothelial permeability caused by exogenous reactive oxygen species and vascular endothelial growth factor. J. Pharmacol. Exp. Ther. 338, 82-91, https://doi.org/10.1124/jpet.111.180620

Jaeschke H., 1995. Mechanisms of oxidant stress-induced acute tissue injury. Exp. Biol. Med. 209, 104-111, https://doi. org/10.3181/00379727-209-43885b

Jiang X.R., Agazzi A., Awati A., Vitari F., Bento H., Ferrari A., Alborali G.L., Crestani M., Domeneghini C., Bontempo V., 2015a. Influence of a blend of essential oils and an enzyme combination on growth performance, microbial counts, ileum microscopic anatomy and the expression of inflammatory mediators in weaned piglets following an Escherichia coli infection. Anim. Feed Sci. Technol. 209, 219-229, https://doi. org/10.1016/j.anifeedsci.2015.08.010

Jiang X.R., Awati A., Agazzi A., Vitari F., Ferrari A., Bento H., Crestani M., Domeneghini C., Bontempo V., 2015b. Effects of a blend of essential oils and an enzyme combination on nutrient digestibility, ileum histology and expression of inflammatory mediators in weaned piglets. Animal 9, 417-426, https:// doi.org/10.1017/S1751731114002444

Jiang X.R., Zhang H.J., Mantovani G., Alborali G.L., Caputo J.M., Savoini G., Dell'Orto V., Bontempo V., 2014. The effect of plant polyphenols on the antioxidant defence system of weaned piglets subjected to an Escherichia coli challenge. J. Anim. Feed Sci. 23, 324-330, https://doi.org/10.22358/ jafs/65668/2014

Lagouri V., Blekas G., Tsimidou M., Kokkini S., Boskou D., 1993. Composition and antioxidant activity of essential oils from Oregano plants grown wild in Greece. Z. Lebensm. Unters. Forsch. 197, 20-23, https://doi.org/10.1007/BF01202694 
Liu Y., Song M., Che T.M., Almeida J.A.S., Lee J.J., Bravo D., Maddox C.W., Pettigrew J.E., 2013. Dietary plant extracts alleviate diarrhea and alter immune responses of weaned pigs experimentally infected with a pathogenic Escherichia coli. J. Anim. Sci. 91, 5294-5306, https://doi.org/10.2527/ jas.2012-6194

Loos M., Geens M., Schauvliege S., Gasthuys F., van der Meulen J., Dubreuil J.D., Goddeeris B.M., Niewold T., Cox E., 2012. Role of heat-stable enterotoxins in the induction of early immune responses in piglets after infection with enterotoxigenic Escherichia coli. PloS ONE 7, e41041, https://doi.org/10.1371/ journal.pone.0041041

Lykkesfeldt J., Svendsen O., 2007. Oxidants and antioxidants in disease: oxidative stress in farm animals. Vet. J. 173, 502-511, https://doi.org/10.1016/j.tvjl.2006.06.005

Maenner K., Vahjen W., Simon O., 2011. Studies on the effects of essential-oil-based feed additives on performance, ileal nutrient digestibility, and selected bacterial groups in the gastrointestinal tract of piglets. J. Anim. Sci. 89, 2106-2112, https://doi. org/10.2527/jas.2010-2950

Mancini-Filho J., Van-Koiij A., Mancini D.A., Cozzolino F.F., Torres R.P., 1998. Antioxidant activity of cinnamon (Cinnamomum zeylanicum, Breyne) extracts. Boll. Chim. Farm. 137, 443-447

NRC, 2012. Nutrient Requirements of Swine. $11^{\text {th }}$ revised Edition. National Academy Press. Washington, DC (USA)

Si W., Gong J., Chanas C., Cui S., Yu H., Caballero C., Friendship R.M., 2006. In vitro assessment of antimicrobial activity of carvacrol, thymol and cinnamaldehyde towards Salmonella serotype Typhimurium DT104: effects of pig diets and emulsification in hydrocolloids. J. Appl. Microbiol. 100, 1282-1291, https://doi. org/10.1111/j.1365-2672.2006.03045.x
Trevisi P., Merialdi G., Mazzoni M., Casini L., Tittarelli C., De Filippi S., Minieri L., Lalatta-Costerbosa G., Bosi P., 2007. Effect of dietary addition of thymol on growth, salivary and gastric function, immune response, and excretion of Salmonella enterica serovar Typhimurium, in weaning pigs challenged with this microbe strain. Ital. J. Anim. Sci. 6, Suppl. 1, 374-376

Ünlü A., Türközkan N., Cimen B., Karabicak U., Yaman H., 2001. The effect of Escherichia coli-derived lipopolysaccharides on plasma levels of malondialdehyde and 3-nitrotyrosine. Clin. Chem. Lab. Med. 39, 491-493, https://doi.org/10.1515/ CCLM.2001.081

Valko M., Leibfritz D., Moncol J., Cronin M.T.D., Mazur M., Telser J., 2007. Free radicals and antioxidants in normal physiological functions and human disease. Int. J. Biochem. Cell Biol. 39, 44-84, https://doi.org/10.1016/j.biocel.2006.07.001

Wang X., Zhao X., 2009. Contribution of oxidative damage to antimicrobial lethality. Antimicrob. Agents Chemother. 53, 13951402, https://doi.org/10.1128/AAC.01087-08

Windisch W., Schedle K., Plitzner C., Kroismayr A., 2008. Use of phytogenic products as feed additives for swine and poultry. J. Anim. Sci. 86, Suppl. E, E140-E148, https://doi. org/10.2527/jas.2007-0459

Zeng Z., Xu X., Zhang Q., Li P., Zhao P., Li Q., Liu J., Piao X., 2015. Effects of essential oil supplementation of a low-energy diet on performance, intestinal morphology and microflora, immune properties and antioxidant activities in weaned pigs. Anim. Sci. J. 86, 279-285, https://doi.org/10.1111/asj.12277 